\title{
Class and Cuisine in Contemporary Britain: The Social Space, the Space of Food and
}

\section{Their Homology}

\author{
Will Atkinson and Christopher Deeming
}

\begin{abstract}
Thirty-five years ago Pierre Bourdieu asserted that food preferences, as much as any other element of culture, are distributed within a space of difference more or less homologous with the social space of class positions. Plumbing data on annual spends on all manner of food items, he detected two key oppositions - a taste for the light versus a taste for the heavy on the one hand and a taste for rich foods versus a taste for healthy and exotic foods on the other - and located their generative principles in differences of volume of capital and composition of capital respectively. Deploying a correspondence analysis of similar data using the 2010 Living Costs and Food Survey, supplemented by data from the 2008 British Social Attitudes survey and the 2003 Cultural Capital and Social Exclusion Survey, we seek to examine whether comparable differences in expenditure and preferences are observable in contemporary Britain and, consequently, to illuminate the current structure of the food space and its homology with class. Ultimately, we conclude that Bourdieu's general model is essentially transposable from 1960s France to the UK at the dawn of the $21^{\text {st }}$ Century, though we put additional emphasis on the ethical dimension of food consumption, and reflect on the prevalent instances of symbolic violence it underpins.
\end{abstract}

\section{Introduction}

Pierre Bourdieu's hefty magnum opus on class and styles of life, Distinction (1984), left few cultural stones unturned. Tastes in objects as variegated as clothes, art, music, decor and partners were all unrepentantly subjected to the same analytical logic - the charting of the maximal space of difference of consumption and the careful mapping of its homology with the space of social positions. Famously, of course, he distinguished two fundamental oppositions structuring lifestyles in 1960's and 70's France: on the one hand, a taste for the rare or exclusive in one form or another versus the 'choice of the necessary', i.e. a taste for the functional or practical; and, on the other hand, a taste oriented around luxury and hedonism versus an aesthetic focussed on self-cultivation and asceticism. The first opposition corresponded closely with how much capital people had in all its varieties - the economic capital of money, wealth etc, the cultural capital of education and symbolic mastery and the social capital of connections - with greater capital allowing distance from necessity and, with that, access to the exclusive. The second opposition, detected Bourdieu, was homologous with the capital composition principle, with those richer in economic capital having access to 
that which is restricted by dint of money while those richer in cultural capital spurn the expensive and consume that which is rare by dint of 'correct' knowledge.

Amongst the numerous and diverse 'stylistic possibles' - or separate domains of consumption and symbolic difference - that Bourdieu explored was perhaps one of the most fundamental of all items of consumption since, in a literal sense, we need it to live: food (Bourdieu, 1984: 177ff). The same logic, though a slightly different method, was applied, and the same principles of differentiation, albeit with particular specifications, emerged: on the one hand, a taste for refined and light foods (e.g. fish) versus a taste for the heavy and substantial, with an emphasis on carbohydrates and plentiful meat, which corresponded with overall volume of capital; and on the other, an opposition, most pronounced among those with higher volumes of capital, between the rich-strong-fatty tastes of those endowed with economic capital (fois gras, pheasant, puddings) and the healthy-lean-exotic tastes of those with greater cultural capital (natural yoghurt, grilled vegetables, unusual cuisines). The underpinning explanatory logic is the same: those with fewest resources seek to fill empty stomachs and sustain energy in the most economical fashion - even if, Bourdieu stressed, they wove this into an ethos of free and easy sociability and conviviality at mealtimes as a challenge to the self-imposed constraints of those looking down on them - while the capitalrich use whatever resources they have to access the exclusive and anti-functional, denigrating the tastes of those opposed to them by virtue of capital composition as either 'crass' or 'pompous'.

This paper seeks to test whether this general patterning, discovered in France over thirty-five years ago, applies in any way to contemporary Britain. We do this through analysis of spending patterns reported in the Office of National Statistics' (ONS) 2010 Living Costs and Food Survey, replicating Bourdieu's own method, plus exploration of additional datasets containing information on food tastes, namely the British Social Attitudes survey for 2008 and the Cultural Capital and Social Exclusion survey data collected in 2003. The hypothesis that there is a class-structured food space does not come from nowhere, it should be made clear, but has been nourished by two sources. The first is previous work indicating that the space of social positions, the space of lifestyles and their homology in the $21^{\text {st }}$ Century United Kingdom are in fact remarkably similar to those detected by Bourdieu in a different country and century (Atkinson, 2010, 2011). The analysis of food - that for which, according to George Bernard Shaw's modern-day Don Juan, there is no sincerer love - will thus deepen this picture of contemporary socio-cultural difference. The second font of the thesis is the plethora of research studies post-Distinction examining the durable nexus between class and 
victuals in the UK which build up a patchy picture without quite providing satisfactory confirmation. It is to a review of this field that we turn first.

\section{Directions since Distinction}

There are, of course, those who have contested the idea that class differences in food consumption are really all that important or interesting. Gartman (1991), for example, took issue with Bourdieu's interpretation of his findings, claiming that the variations in food expenditure and tastes documented were hardly significant compared to disparities in

preferences for art or music - his Frankfurt-style Marxist sympathies leading him to argue that the material differences reflected by food spends were more or less homogenous within the non-propertied class. In long-term historical perspective, too, it might be claimed that differences are declining in inverse ratio to the increasing variety of foodstuffs that have become available to pretty much everyone within Western societies thanks to rising affluence and globalisation (Mennell, 1995), linking up implicitly with various proclamations of increased individual reflexivity in a context of augmented choice, at least among denizens of the affluent core in the world system (Giddens, 1991; Beck, 1992). Nevertheless, the general consensus within epidemiology and the sociology of food is that class differences are still there clear enough and that they flow from particular orientations grounded in possession of resources. Just how adequately existing research can be taken together as evidence of a fully Bourdieu-style multidimensional homology, however, is more questionable, largely because of the limited definitions of 'class' deployed.

The problem is most pronounced in qualitative research where the need for stark comparisons often necessitates use of simple binary classifications - 'middle class' versus 'working class', for example - sometimes with little real elaboration of criteria of inclusion (see e.g. DeVault, 1994; Fox et al, 2009; Wills et al, 2011). We thus learn that those rich in valued resources, with their distance from necessity furnishing a certain perception of the possible, spend freely on food, ably decode and keenly follow the latest scientific and media advice on 'healthy eating', display a preference for exotic foods, expensive brand-name cooking sauces and fresh fish, put a lot of emphasis on variety, healthiness, experimentalism and spice - rejecting what they see as 'plain' food - and underscore discipline, control, regulation and development of valuable dispositions amongst children. We also learn, by contrast, that those without such resources keep a keen eye on bargains and compare prices, are rather more ambivalent about discourses of 'healthy eating', prioritise simply 'getting fed', which might include consuming quick-and-easy frozen food or microwave meals, focus 
on the 'here and now', since present conditions do not facilitate projection too far into the future, and give their children autonomy and responsibility for their own diets as a modest source of freedom (cf. Atkinson, 2012; Atkinson and Bradley, 2013). All very useful evidence of the effect of volume of capital on food consumption, but we get little insight into the tastes and practices of more intermediate zones of social space or the difference capital composition might make - is the emphasis on healthy living as pronounced among those richer in economic than cultural capital, for instance? And is the sense of freedom from necessity as evident amongst those richer in cultural capital than economic capital?

It might be thought that quantitative research, since its larger sample sizes means it does not have to draw such bold oppositions, can help plug the gaps. Unfortunately, however, the measures of class mobilised still only unveil part of the story. Epidemiological studies, while routinely confirming a division between the health-conscious capital rich and the highcalorie-consuming capital poor, have long been hamstrung by their vague and simplistic notion of 'socio-economic status', sometimes measured using income, sometimes education, sometimes prestige, sometimes occupation - but not usually taken together to find more nuanced combinations, patterns and thus causal processes (see, most famously, Marmot, 2005; Wilkinson and Pickett, 2009). Within the sociology of food the situation has not been much better. Charles and Kerr (1988), for example, used the old UK Registrar-General's scheme based on a basic five-tier hierarchy of occupations, but essentially ended up comparing professionals - oriented toward health, taste, experiment and vegetarianism and plumping for pasta, rice, fresh fruit and vegetables, wholemeal bread and wines and spirits and the working class - focussed on eating 'proper meals' (cf. Murcott, 1983) and more likely to eat potatoes, chips and tinned food, i.e. heavy, substantial carbohydrates and convenient foods. Even in research expressly designed to try and test or find some kind of evidence for Bourdieu's thesis ill-fitting measures of class are used. So we find Tomlinson (1998), in his factor analysis of food expenditure, also using the one-dimensional RegistrarGeneral's scheme to unearth higher-class tastes for fruit, salad, fish, chicken and coffee and lower-class tastes for 'junk' (chips, crisps, fried food, processed meats) - though this was an improvement on his earlier work deploying a four-category Marxist measure of class and mapping a meat/carbohydrates opposition on to the bourgeoisie/proletariat divide (with managers and petty bourgeoisie being close to one or the other) (Tomlinson, 1994). Again, no one is denying these studies indicate that differences of volume of resources generate differences of taste, but they may also be obscuring the full tableau of differentiation. 
A step in the right direction came with the work of Savage et al (1992), who, drawing explicitly on Bourdieu but also Erik Olin Wright, took an interest in internal differences within the 'middle class' and their impact on consumption. Large and small property owners were thus distinguished from professionals, rich in cultural capital, and managers, rich in 'organisational assets', i.e. forms of advantage derived from positions of authority at work, and cultural differences were charted. There were, however, distinct analytical shortcomings in this work. The effects of income and education, for example, were examined individually, making it difficult to unpick the interaction or differentiation by capital composition - thus we find that both those high in income and the highly educated have a taste for foreign restaurants and champagne, without knowing for sure whether money or symbolic mastery is the generative element; the indicators of food tastes are limited to favourite restaurants and drinks alone; and the occupational categories used to render the differences are hardly powerful indicators of cultural difference since they reveal contradictory ('postmodern') and 'indistinctive' lifestyles. Tomlinson and Warde (1995), in their use of Savage et al's categories to study a broader range of alimentary tastes, confirm this last point, arguing that managers are too heterogeneous a category and organisational assets too poor a discriminator of taste to be especially useful - which is not surprising, since from a Bourdieusian point of view 'organisational assets' are not fundamental to classed conditions of existence and thus taste, even if, contrary to Savage et al's (1992: 103) claim that Bourdieu was ignorant of them altogether, they may well constitute capitals within specific workplaces qua fields (cf. Bourdieu, 2005).

By the turn of the millennium, however, the debate had moved on. The new thesis on the block - launched by Richard Peterson (1992) and recasting the increased-variety argument - was omnivorousness. The source of social recognition in late modernity, it was claimed, had morphed. No longer was a taste for classical music or opera the mark of distinction; a taste for the different, the diverse and the mixed made available by global media and communications now served that function. Initially confined to music, eventually the influence of this simple hypothesis spread to cover all domains of consumption and, thus, was duly applied to the very topic from which the metaphor sprang. However, the binary nature of the omnivore/univore thesis and its translation within the sociology of food into preferences for variety of restaurants when eating out have limited subsequent research, not only obscuring broader orientations toward food as part of a whole class ethos but encouraging a regression of measures of class to more or less unidimensional affairs. Thus, Warde and Martens (2000) made the case that higher education and higher income tended to correspond 
to a taste for eating at foreign restaurants, but declined to examine how their differential combination may shape patterns, and in other instances they deployed the Nuffield class schema, which is somewhat unhelpful for tapping capital composition (see also Warde et al, 1999). Bennett et al (2008), on the other hand, watered down the omnivore thesis in relation to dining out by charting a hierarchy of specific cuisines, from French restaurants and exotic foods at the top through more 'familiar' foreign fare to 'pub grub' and fast food at the bottom, and noting only that the more privileged had a slightly wider experience of restaurants. Once again, however, problems of their analysis and reliance on the Goldthorpeinspired National Statistics Socio-Economic Classification denied the possibility of making full sense of the pecking order of palates by preventing examination of differences of taste within classes on the basis of balance of capital (similar criticisms can be applied to Savage et al, 2013). ${ }^{1}$

Is there anyone, then, who has conducted a more satisfactory assessment of the impact of class á la Bourdieu on food tastes, making room for a refined analysis of not only volume of capital but composition too? The answer to that is yes, but with qualification. Prieur et al (2008) and Rosenlund (2009) have, using multiple correspondence analysis, constructed models of social space, symbolic space and their homology, unearthing the difference one's balance of capital makes to the tastes associated with volume of capital. To be precise, those low in capital tended to emphasise traditional cooking and having 'plenty of food', while those in the higher reaches of the social space either opted for the new, the exotic and the healthy if they were high in cultural capital or the expensive if they were rich in economic capital. The trouble is their data is Danish in one case and Norwegian in the other, so they tell us nothing about British tastes. Moreover, food tastes - to be more specific, views on kinds of food participants like to serve to guests - were only one element in the models of the space of lifestyles in general, and lacking was the real digging around in the details of food expenditures and tastes necessary for focussed construction of the space of foods itself. Vandebroeck's (2013) detailed study of the relationship between class and the body is better in that regard, but since its empirical materials are Belgian it cannot be readily transposed to the UK.

\section{Constructing the Spaces}

A satisfactory test of the applicability in $21^{\text {st }}$ Century Britain of Bourdieu's model of the homology between the social space and the food space, therefore, has failed to surface. We aim to go at least some way toward rectifying this scenario by replicating Bourdieu's own 
method of tapping into the homology: the detailed breakdown of family food expenditure by class (see Bourdieu, 1984: 181-2, 188-9). To do this we draw primarily on the 2010 sweep of the ONS Living Costs and Food Survey $(n=5,320)$, hereafter LCF, a module of the Integrated Household Survey which tracks household expenditure over a two-week period using diaries from each member. The data is not without its limits: being measured at the household level, we have no practical way of taking into account the differential distribution of food within the household, which often falls along gendered and generational lines (see e.g. Charles and Kerr, 1988); there is no way to gauge the expense of individual items purchased, only the total spend on the category; and we have no insight into precisely how or when the items are prepared and consumed. All we can do is acknowledge those limits, bear them in mind when making sense of the findings and be circumspect in our conclusions. On the other hand, since these features of the survey conspire to obfuscate any insight into the mode of consumption, rendering the analysis of expenditure alone rather conservative in its capacity to detect class differences, any differences that are detected become all the more telling. We also supplement the main analysis of the LCF with data drawn from a module of the 2008 British Social Attitudes (BSA) Survey $(n=2,250)$ on what influences people's choice of foods, indicating perceptions of the possible and desirable constituting habitus, and data on favourite ilk of eatery from the 2003 Cultural Capital and Social Exclusion (CCSE) survey $(n=1,564)$ that underpinned Bennett et al's (2008) analysis.

Since we are examining average weekly expenditure on a large selection of foodstuffs by class the optimal method is simple correspondence analysis (CA), a form of factor analysis detecting underlying patterns in large cross tabulations and transforming them into a multidimensional space. It is, in fact, the method Bourdieu tended to use before multiple correspondence analysis, the statistical method most commonly associated with his name, was developed, even though he opted to present his own food data in tabular form. However, to remedy the stumbling blocks charted above on measurements of class, as well as limits of the LCF (particularly that it has no variables tapping cultural capital possession), we use a class scheme specifically designed to approximate maximum differences in volume and composition of capital in contemporary Britain. ${ }^{2}$ Premised on an aggregation of the ONS unit-level Standard Occupational Classification variable, it comprises three classes, each with four internal class fractions: (i) the dominant, including business executives, the cultural dominant (teachers, intellectuals, cultural producers, socio-medical services, etc.), professions and white-collar workers (IT specialists, surveyors, etc.); (ii) the intermediate class of lower managers and proprietors (LMPs), cultural intermediaries (nurses, paramedics, youth 
workers, counsellors), technicians and administrators; and (iii) the dominated, covering skilled workers, caring services (nursery nurses, care workers), sales workers and manual workers. Some basic indicators of capital are given in Table 1, though more detailed analysis using further indicators deriving from a multitude of sources (the Labour Force Survey, the Wealth and Assets Survey and such like) and, ultimately, determining the relational positioning of the class fractions, including the three-class clustering, is presented elsewhere (Atkinson and Rosenlund, 2014). Suffice it to say that business executives and the 'cultural dominant' are opposed to manual workers on one axis, but also to each other on a second axis which also opposes lower managers and proprietors (or LMPs) to cultural intermediaries and skilled workers to workers in caring services. This second opposition, polarising those possessing primarily economic capital and those possessing primarily cultural capital (as measured by educational qualifications), is also highly homologous with gender, women tending to be found disproportionately within the sections richer in cultural capital but poorer in economic capital, and men among the economically rich. Cultural capital, symbolic mastery and the lifestyle that flows from it are thus deeply entwined with dispositions and perceptions of 'femininity', and economic capital and its accoutrements with 'masculinity', often revolving around the same thought-structuring binaries of soft/hard, mind/matter, emotion/reason and so on.

\section{[Table 1 here]}

\section{The Light and the Heavy, the Rich and the Lean}

The analysis of correspondences reveals that two axes, on which our attention shall focus, account for 61 percent of the total variance in household alimentary expenditure (Figure 1, Tables 2 and 3). The premier opposition, responsible for 50 percent of the variance, appears to distinguish the more substantial carbohydrates and fattier and saltier foods from leaner meats and, to different degrees, fruit and vegetables. At the one end, therefore, gather items like bread - a heavier, staple carbohydrate usually involving little or no cooking and 'fuss' processed meats and pork, which, thanks to the way they are manufactured, are both usually fairly salty meat varieties. Full-fat milk is also to be found at this pole, as are soft drinks such as cordials and carbonated potations, often of a sugary nature - and, among the vegetables, potatoes and tubers (yams, cassava etc), the heaviest and most filling of their category. At the other end of the axis, in direct contrast, stands fish - which, notwithstanding the various types and ways it can be prepared, is the leanest and lightest of all meats - and a 
whole host of fruit and vegetables. The latter are, however, of a particular type: amongst fruits it is generally the lightest and most fiddly to eat - citrus fruits, stone fruits (peaches, plums, cherries), berries and so on - as opposed to bananas and apples, which take little effort and a fairly substantial, and among vegetables it is the light and delicate leaf and stem vegetables and vegetables grown for their fruit (e.g. tomatoes) that cluster at the pole.

\section{[Figure 1 here]}

[Tables 2 and 3 here]

If the first axis opposes the heavy-fatty-salty-sugary and the light, then the second axis, accounting for 11 percent of the variance, crosscuts it with a second set of distinctions. Here we find, among carbohydrates, cakes and puddings opposed to rice; among meats, lamb - an expensive meat on account of its conditions of production and high exports often sold on its richness - opposed to poultry, fish and ham; whole milk opposed to low-fat milk; cheese opposed to yoghurt; coffee opposed to tea; and, nestling alongside lamb, cheese and cakes, ice cream and mineral water. There is much in this axis to warrant a cautious interpretation of it as opposing the expensive (lamb, bottled water) or rich (cheese, coffee etc) and the bland, or at least less-rich, taking different forms as it travels along the first axis, with the 'bland' pole also being characterised by leaner foods.

Examination of the homologies with class reveals a few themes. It is, for one thing, immediately clear that the primary axis approximates capital volume. The heavy, the substantial, the functional, the cheap and the sugary/salty are most closely associated with the dominated class, indicating a prioritisation of matter over manner rooted in particular conditions of existence, while the dominant class, no doubt thanks to their relative distance from necessity, are pulled toward the light and fiddly, though with the cultural dominant pulled further up this pole than the business executives. The second axis, moreover, roughly reflects capital composition and, inseparably, gender. ${ }^{3}$ Yet, without being so foolhardy as to try to draw definitive conclusions from a solitary model based on a single sample, there are a few particularities to mention: the professions seem to be the most inclined towards toward light-yet-rich foods, rather than, as might have been supposed, the business executives, and the technicians and cultural intermediaries are the most inclined toward the non-rich/lean, followed by administrators and caring services, rather than the cultural dominant - perhaps, one might conjecture, indicating, either in isolation or combination, the asceticism associated with cultural capital, a petit-bourgeois ethos of self-restraint (moderating the intake of 
'luxuries') and, among cultural intermediaries, administrators, and caring services in particular, the attention to bodily care and appearance disproportionately demanded in these feminine class fractions. White-collar workers also appear to have food tastes closer to those of the petite bourgeoisie, nestling close to the origin of the food space. Finally, it has to be acknowledged that statistical dispersion of the class fractions is not especially broad - the distances recorded on the two axes, especially axis two, are relatively modest - but, nevertheless, they might just be pulled in their respective directions enough for it to be perceptible in everyday classifications of practice.

Although not entered into the CA, alcoholic drinks bought for consumption at home follow a highly homologous pattern (Table 4). ${ }^{4}$ Relative spend on spirits - i.e. 'hard' drinks tends to roughly decrease with rising volume of capital, and especially cultural capital, opposing professions (10.2 percent) to manual workers (20 percent), skilled trades (24.2 percent) and sales workers (26.5 percent) but also, within their own class, to white collar workers (19.9 percent), and cultural intermediaries and administrators to technicians and LMPs. Beer and lager consumption follows the same pattern, being associated with lower volumes of capital - manual workers spend over twice as much, in relative terms, on beer/lager than the professions and cultural dominant, and a little more in absolute terms too. Conversely, consumption of wine increases with volume of capital, and with a higher proportion of cultural capital (and women within the class fraction) than economic capital (and men within the class fraction). Thus the cultural dominant (58.1 percent) and cultural intermediaries (57.8 percent) are most opposed to manual workers (36.3 percent) and skilled trades (33.8 percent), but differences of capital volume and composition are evident within each class too. Champagne and sparkling wine expenditure also follows volume of capital, but this time it corresponds more closely with economic capital. The professionals spend almost a fifth of their alcohol budget on it, or $£ 122$, compared with just one percent - a mere $£ 3.40$ per annum - among manual workers, but within classes there are differences between fractions, the economically richest and most masculine - the skilled trades, LMPs and business executives - all having higher expenditure than the culturally richer and more feminised fractions.

[Table 4 here]

\section{The Possible and the Desirable}


To this reconstruction of tastes we can now add our supplementary ingredients, including, first of all, the BSA data on the factors influencing choice of foods, i.e. that which enters consciousness (or at least which people think should enter consciousness) when considering what to buy as an indicator of perceptions of the possible and thence the desirable, themselves indicative of habitus attuned to specific conditions of existence (Table 5). Notwithstanding the general patterning of orientations - quality, taste, health and price seem to be the most salient factors across the board - some fairly stark oppositions emerge, especially if measured by distance from the average rate of the factor being mentioned. The dominant are generally most likely to emphasise quality/freshness, taste, healthiness and various ethical issues (animal welfare, Fair Trade/localism, impact on the environment and so on) and least likely to be concerned about price, while the dominated are more concerned about cost and least concerned about everything else, clearly indicating the difference between an orientation grounded in distance from necessity, with the freedom to be able to emphasise richness and lightness - aesthetic but also ethical - and an orientation toward meeting the demands of necessity. Interestingly, however, the intermediate class are also likely to emphasise cost, fitting with their image as the class who have to make themselves small (petite) by saving and so on to become bourgeois (Bourdieu, 1984: 338).

\section{[Table 5]}

On top of this general opposition, however, there are further differences between class fractions by capital composition. Within the dominant class, for example, the cultural dominant are more likely to emphasise freshness, health, avoidance of additives, vegetarianism, organic, animal welfare and packaging amounts - considerations flowing from their symbolic mastery, perhaps, i.e. their relative mastery of and interest in abstract scientific and medical discourses, whereas the business executives appear to attach least relevance to food being low fat and are less concerned about the ethical and political dimension, but they put greater emphasis than others on presentation - a sign of nothing other than distance from necessity - and convenience. Within the intermediate class too, the fraction richer in cultural capital - as well as technicians, richest in technical capital - put greater emphasis on freshness, health, animal welfare, fair trade and environmental impact, but also convenience and value, while the economically richest fraction are least interested in health, fair trade and environmental issues (as well as convenience) but do put a premium on taste, presentation and - possibly, since they are usually fairly expensive but not unambiguously linked to 
improved health content or flavour, as a sign of distinctiveness - organic foods. The dominated class, finally, also display internal variation, with the caring and personal services, richest in cultural capital, being most likely to consider health, additives, animal welfare, fair trade and packaging and to be vegetarian, but also most likely to emphasise cost (as the economically poorest fraction) and presentation (since aesthetic appearance is often central to many of these jobs). The skilled trades, richest in economic capital, are the least oriented toward many of the ethical issues and the least likely to consider price.

A second accompaniment to the analysis so far - often the main course in many studies - is the CCSE data on eating out (specifically, eating a main meal out for pleasure). This is, to be clear, an activity undertaken most frequently by those more distant from necessity: business executives and white-collar workers are most likely to dine out at least once a week, and other fractions of the dominant class are likely to eat out once a month or so, while the dominated class are more likely to eat out once or a few times a year (Figure 2). That established, however, what kinds of place are people going to eat at (Table 6)? Most popular overall are pubs/wine bars/hotels - an unfortunately broad and ambiguous category followed by Chinese/Thai restaurants (which strike us as quite distinct) and then Italian and Indian restaurants. Cafes, pizza houses, fast food, fish and chips and steakhouses traditional, cheap or 'no frills' eateries - are less popular as a whole, as are the bastions of haute cuisine, French restaurants. Yet there are evident class differences: cafes, pizza houses, fast food and fish and chips are most popular amongst the dominated class, and to a lesser extent the cultural-capital poor LMPs, while steakhouses - masculine, no airs and graces, but not so cheap - are more likely to be favoured by skilled trades. On the other hand, French restaurants are preferred at a vastly disproportionate rate by the professions, and secondarily by the business executives - i.e. the two economically richest fractions in the social space and then other members of the dominant class, while Italian restaurants also seem more popular among higher regions of social space, especially where the composition of capital is balanced, suggesting they require some degree of symbolic mastery or money as an entry ticket but not enough to mark out those with their capital stocks tipped one way or the other. In line with the dispositions so far charted, moreover, and in direct opposition to the tastes of the skilled trades, the cultural dominant are most likely to favour vegetarian restaurants. The dominant class fractions are also generally the least likely to eat at the most popular style of eatery, the pub/wine bar/hotel, suggesting that this - along with the other, less popular lowcost and uncomplicated eateries - may be the 'popular' against which the 'distinguished' and rare (French restaurants and vegetarian restaurants) are opposed. 
[Figure 2]

[Table 6]

\section{Discussion: Ethics, Health and Symbolic Violence}

All in all, then, everything would appear to indicate that the food space in contemporary Britain and its homology with the social space of classes are remarkably similar to those documented by Bourdieu for France fifty years ago. The light and exclusive are still opposed to the heavy, the cheap and the filling, and the rich and expensive are still opposed to the lean and the healthy - which is not to say that every meal or morsel eaten by the homologous class fractions exemplify these aesthetics, only that they tend to. Perhaps the main novelty, along with the addition of restaurant/cuisine tastes and re-specification of paradigmatic items (or symbols) in line with the different country and year (and data), is the increased importance attached to the ethical dimension of food consumption among those disproportionately endowed with cultural capital. Doubtless some might see this as a result of the steady rise of 'post-materialist' political issues and the switch from production to consumption as the main site of political action and power in the West (e.g. Inglehart, 1990; Giddens, 1991). Yet even if that were so - and there is evidence to say the picture is rather more complex than that, not only because of the empirical faults of the post-materialism thesis (Majima and Savage, 2008) but because similar homologies can be found as far back as ancient Greece (Vandebroeck, 2013) - it would appear from our analysis that so-called post-material concerns, at least as they play out in relation to food, are more likely to be the preserve of those relatively distant from material necessity and in possession of legitimated ways of knowing and thinking, since they have the freedom and the symbolic mastery to fringe the most concrete practical act of buying food with awareness of global supply chains and abstract discourses of 'animal rights', 'global poverty', 'global warming' and so on (cf. Adams and Raisborough, 2008).

In this respect the concern for the ethical dimension may well stem from the same set of generic class dispositions as the concern for health - or more accurately for the lean, nutritious and low-fat since the dominated still perceive their diet as 'healthy' in its own contrasting way, i.e. as keeping themselves fed rather than going without (Atkinson and Bradley, 2013). Like the orientation for the lean, it indicates a disposition to control, discipline or regulate consumption born of a capacity to project oneself and one's doings into the longer-term future - taking the body or the environment etc. as ends in themselves rather 
than means to practical ends - in turn founded on a relative distance from the demands and urgencies of material necessity and mastery of, and thus interest in, specific symbolic discourses concerning the body and the world (itself developed in part thanks to relative distance from necessity) (cf. Wills et al, 2011). Working at multiple levels, this disposition guides unreflected bodily intentionality and 'absorbed coping', as Hubert Dreyfus calls it the automatic checking of labels, for example - as well as projection - considerations on what to buy, making a shopping list, planning a meal - and pairs perceived food items with a greater or lesser sense of 'I can have it', 'I want it' or 'that's my kind of thing'.

Variations in alimentary dispositions are not innocent trifles. They are no less bound up with symbolic power and symbolic violence than differences in taste for artworks, music, films, sports or clothes. Being oriented around control and restraint, the dispositions of the (cultural) dominant lead their bearers (and those just below them whose ethos is oriented toward being like them) to define the dispositions of the dominated - their 'negative foil' - in terms of lack of control, lack of restraint, lack of forethought or, in a word, of excess, as if less lean or ethical diets were simply bad choices made by autonomous or 'stupid' people rather than the product of a 'here and now' practical orientation attuned to the harder conditions of life and experiences associated with less capital (see Adams and Raisborough, 2011). ${ }^{5}$ Hence the many reality television shows, from You Are What You Eat to Honey We're Killing the Kids, parading members of the dominated class as shamelessly thoughtless and out of control in their food habits - as judged by an 'expert' from a completely different section of the social space - and, in the process, attempting to propagate a specific disposition as the universally legitimate one (Skeggs and Wood, 2011). Hence also the diatribe a few years ago of Jamie Oliver - feted celebrity chef and supposed saviour of the UK's children through his high-profile mediatised and politician-exciting intervention on the content of school dinners - against parents who feed their children food of which he disapproves on health grounds (e.g. crisps, fizzy drinks): they are, according to him, 'arseholes' and 'tossers' who do nothing but thoughtlessly feed their children 'shit' yet selfishly splash out on beer for themselves (see O'Neill, 2008). Hence, finally, the more subtle yet pervasive political assumption, as concretised in public health campaigns such as 'Change4Life', that obesity and ill-health - seen largely as economic problems ('a drain on the NHS') - are fixable simply through telling people to make different choices, as if those choices depend solely on information available rather than the principle of first-things-first, which then has the effect of inducing guilt when those choices cannot be made. If the 'art of eating and drinking' was 
once an area in which the dominated could challenge the legitimacy of the dominant way of life (Bourdieu, 1984: 179), this seems less the case in early $21^{\text {st }}$ Century Britain.

\section{Acknowledgements}

The research on which this article is based was funded by the British Academy. We are grateful to the anonymous referees and to members of the Network for Studies of Cultural Distinctions and Social Differentiation for their helpful comments and suggestions on earlier versions of the paper.

\section{Notes}

1. Bennett et al did also attempt to analyse data on dining at home, claiming no clear differences by cultural capital came out, but their data on it was so meagre that no firm conclusions could really be drawn.

2. In the LCF, the class fraction variable attaches to the occupation of the household reference person (HRP) as defined by the ONS, i.e. the person within the household who owns the home, pays the rent or has the highest income. Normally we would prefer to isolate individual class position, but since we are focussing on household expenditure - in which all parties (unequally) purchase items contributing toward collectively eaten meals - we admit it on this occasion. In 39 percent of cases the HRP was female, and these tend to fall disproportionately within the class fractions with a higher rate of feminisation, such as the cultural dominant, the cultural intermediaries and the caring services. In the BSA and CCSE surveys, the class fraction variable attaches to individuals.

3. When the dominated class are excluded from the analysis the general structure of the model stays the same, but the weighting of the percentage explained between the two axes shifts to 39 percent for axis one and 19 percent for axis two, suggesting that the capital composition principle increases in salience with height in social space.

4. An initial solution contained both food and alcoholic drinks, but the drinks modalities (especially beer) tended to stretch and contribute an excessive amount to the axes, obscuring the differences between food items. A similar effect occurred when tastes for restaurants and reasons for food purchases were included, suggesting that these, along with tastes relating to alcoholic drinks, are more 'classifying' than food expenditures per se. This is not surprising 
given the already-stated conservative nature of the food expenditure data, so we opted to focus on the latter alone in order to maximise visibility of differences.

5. Interestingly, symbolic violence exerted by the economically dominant against the dominated (e.g. denigration of 'cheap' food) seems rather less well researched. This is perhaps a symptom of the overemphasis in research inspired by Bourdieu on cultural capital at the expense of economic capital, itself bound up with faltering or absent recognition of the internal heterogeneity of the dominant class.

\section{References}

Adams, M. and Raisborough, J. (2008) 'What Can Sociology Say About FairTrade?' Sociology, 42(6): 1165-82.

Adams, M. and Raisborough, J. (2011) 'The Self-Control Ethos and the 'Chav', Culture and Psychology, 17(1): 81-97.

Atkinson, W. (2010) Class, Individualization and Late Modernity: In Search of the Reflexive Worker. Basingstoke: Palgrave Macmillan.

Atkinson, W. (2011) 'The Context and Genesis of Musical Tastes: Omnivorousness Debunked, Bourdieu Buttressed’ Poetics, 39 (3): 169-186.

Atkinson, W. (2012) 'Economic Crisis and Classed Everyday Life: Hysteresis, Positional Suffering and Symbolic Violence' in W. Atkinson, S. Roberts and M. Savage (Eds.) Class Inequality in Austerity Britain: Power, Difference and Suffering. Basingstoke: Palgrave Macmillan, pp. 13-32.

Atkinson, W. and Bradley, H. (2013) Ordinary Lives in Contemporary Britain. SPAIS working paper no. 8-13, University of Bristol, available at http://www.bristol.ac.uk/spais/research/workingpapers/

Atkinson, W. and Rosenlund, L. (2014) Mapping the British Social Space: Toward a Bourdieusian Class Scheme. SPAIS working paper no. 02-14, University of Bristol, available at http://www.bristol.ac.uk/spais/research/workingpapers/

Beck, U. (1992) Risk Society. London: Sage.

Bennett, T., Savage, M., Silva, E., Warde, A., Gayo-Cal, M. and Wright, D. (2008) Culture, Class, Distinction. London: Routledge.

Bourdieu, P. (1984) Distinction. London: Routledge.

Bourdieu, P. (2005) The Social Structures of the Economy. Cambridge: Polity.

Charles, N. and Kerr, M. (1988) Women, Food and Families. Manchester: Manchester University Press. 
DeVault, M. (1994) Feeding the Family. Chicago: University of Chicago Press.

Fox, R., Nicolson, P and Hefferman, K. (2009) 'Pregnancy Police? Maternal Bodies, Surveillance and Food' in P. Jackson (Ed) Changing Families, Changing Food. Basingstoke: Palgrave Macmillan, pp. 57-74.

Gartman, D. (1991) 'Culture as Class Symbolization or Mass Reification?' American Journal of Sociology, 97(2): 421-47.

Giddens, A. (1991) Modernity and Self-Identity. Cambridge: Polity.

Inglehart, R. (1990) Culture Shift in Advanced Industrial Society. Princeton: Princeton University Press.

Majima, S. and Savage, M. (2007) 'Have There Been Culture Shifts in Britain?' Cultural Sociology, 1(3): 293-315.

Marmot, M. (2005) Status Syndrome. London: Bloomsbury.

Mennell, S. (1995) All Manners of Food ( $2^{\text {nd }}$ Ed). Urbana: University of Illinois Press.

Murcott, A. (1982) 'On the Social Significance of the 'Cooked Dinner' in South Wales' Social Science Information, 21(4/5): 677-96.

O’Neill, B. (2008) 'Roasting the Masses' The Guardian, 27 ${ }^{\text {th }}$ Augsut, 2008, available at http://www.theguardian.com/commentisfree/2008/aug/27/oliver.foodanddrink (Accessed 18/02/2014).

Peterson, R. (1992) 'Understanding Audience Segmentation: From Snob to Omnivore' American Sociological Review, 61: 900-7.

Prieur, A., Rosenlund, L. and Skjott-Larsen, J. (2008) 'Cultural Capital Today: A Case Study from Denmark’ Poetics, 36(1): 45-71.

Rosenlund, L. (2009) Exploring the City with Bourdieu. Saarbrücken: VDM Verlag.

Savage, M., Barlow, J., Dickens, P. and Fielding, T. (1992) Property, Bureaucracy and Culture. London: Routledge.

Savage, M. et al (2013) 'A New Model of Social Class?' Sociology, 47(2): 219-50.

Skeggs, B. and Wood, H. (2011) Reacting to Reality Television. London: Routledge.

Tomlinson, M. (1994) 'Do Distinct Class Preferences for Foods Exist? British Food Journal, 96(7): 11-17.

Tomlinson, M. (1998) 'Changes in Tastes in Britain, 1985-1992' British Food Journal, 100(6): 295-301.

Tomlinson, M. and Warde, A. (1995) 'Taste Among the Middle Classes, 1968-88' in T. Butler and M. Savage (Eds.) Social Change and the Middle Classes. London: UCL Press, pp. 241-56. 
Vandebroeck, D. (2013) Harnessing the Flesh. Unpublished PhD thesis, Free University of Belgium, Brussels.

Warde, A. and Martens, L. (2000) Eating Out: Social Differentiation, Consumption and Pleasure. Cambridge: Cambridge University Press.

Warde, A., Martens, L. and Olsen, W. (1999) 'Consumption and the Problem of Variety' Sociology, 33(1): 105-27.

Wilkinson, R. and Pickett, K. (2009) The Spirit Level. London: Penguin.

Wills, W., Backett-Milburn, K., Roberts, M.-L. and Lawton, J. (2011) 'The Framing of Social Class Distinctions Through Family Food and Eating Practices' The Sociological Review, 59(4): 725-40. 


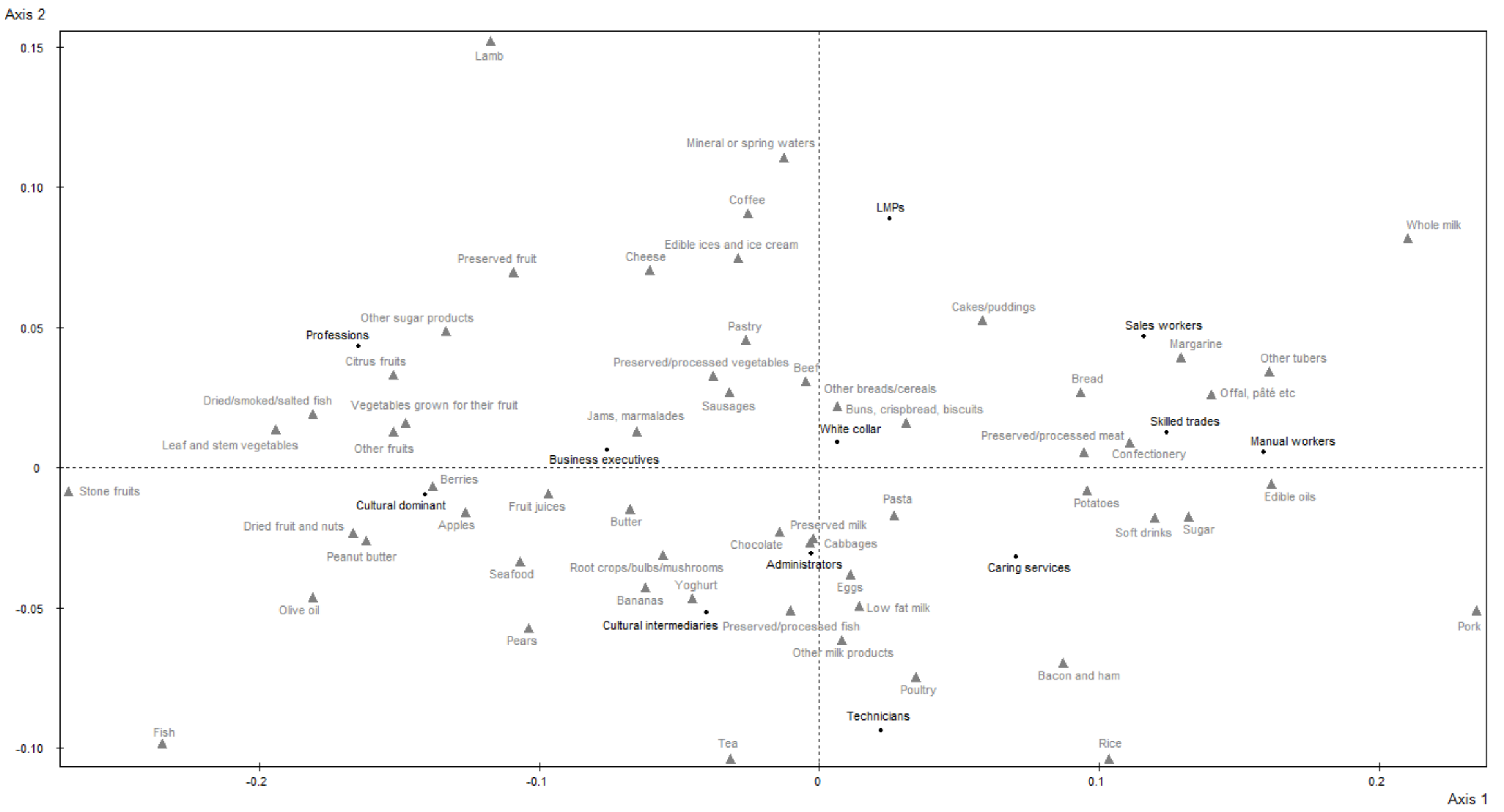

Figure $1 \mathrm{CA}$ of foodstuffs and class fractions, plane of axes 1 and 2 


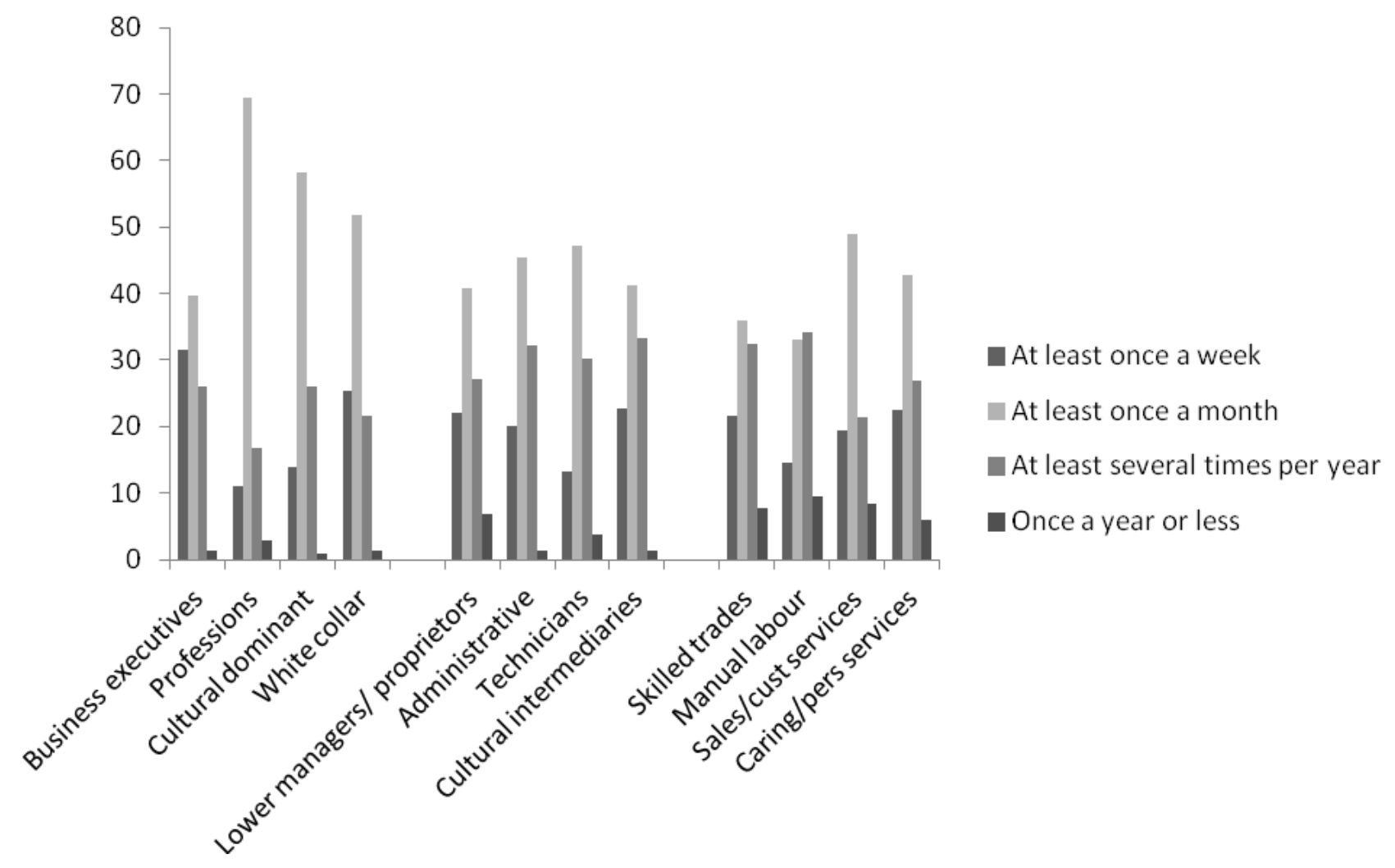

Figure 1 Frequency of eating out (\%) 
Table 1 Class fractions in Britain

\begin{tabular}{|c|c|c|c|c|c|c|c|}
\hline Class & Class fraction & $\begin{array}{c}\text { Percentage of } \\
\text { working } \\
\text { population }\end{array}$ & $\begin{array}{l}\text { Higher education } \\
(\%)\end{array}$ & $\begin{array}{l}\text { Postgraduate } \\
\text { degree }(\%)\end{array}$ & 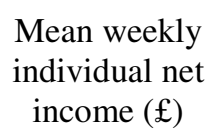 & $\begin{array}{l}\text { Gender ratio } \\
\text { (Male/female) }\end{array}$ & $\begin{array}{c}\text { Capital } \\
\text { composition }\end{array}$ \\
\hline \multirow{4}{*}{ Domin } & Business executives & 5.9 & 50.6 & 13.9 & 742 & $75 / 25$ & $\mathrm{EC}+, \mathrm{CC}-$ \\
\hline & Professions & 4.9 & 76.2 & 25.1 & 633 & $64 / 36$ & \\
\hline & White-collar & 9.6 & 49.9 & 12.0 & 483 & $63 / 37$ & 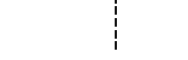 \\
\hline & Cultural dominant & 9.9 & 82.5 & 39.2 & 431 & $38 / 62$ & $\mathrm{EC}-, \mathrm{CC}+$ \\
\hline \multirow{4}{*}{ Interm } & LMPs & 5.1 & 26.8 & 5.4 & 428 & $65 / 35$ & $\mathrm{EC}+, \mathrm{CC}-$ \\
\hline & Technicians & 4.2 & 38.6 & 9.3 & 441 & $82 / 18$ & 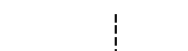 \\
\hline & Administrators & 11.0 & 21.2 & 3.1 & 265 & $23 / 77$ & 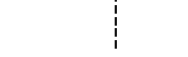 \\
\hline & Cultural intermediaries & 4.6 & 45.9 & 10.3 & 349 & $24 / 76$ & $\mathrm{EC}-, \mathrm{CC}+$ \\
\hline \multirow{4}{*}{ Domin } & Skilled trades & 10.6 & 5.0 & 1.0 & 329 & $90 / 10$ & $\mathrm{EC}+, \mathrm{CC}-$ \\
\hline & Manual labour & 17.0 & 7.8 & 0.7 & 232 & $67 / 33$ & 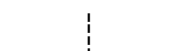 \\
\hline & Sales workers & 7.8 & 12.0 & 2.2 & 188 & $37 / 63$ & 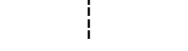 \\
\hline & Caring services & 9.1 & 16.1 & 1.9 & 209 & $18 / 82$ & $\mathrm{EC}-, \mathrm{CC}+$ \\
\hline
\end{tabular}

Source: Labour Force Survey 2013, Second Quarter. Weighted for populations estimates. 
Table 2 Contributions of variables to the axes*

\begin{tabular}{|c|c|c|c|c|c|c|c|c|}
\hline Food item & Axis 1 & Axis 2 & Food item & Axis 1 & Axis 2 & Food item & Axis 1 & Axis 2 \\
\hline Rice & 0.931 & 4.238 & Low fat milk & 0.070 & 3.856 & Leaf and stem vegetables & 7.449 & 0.163 \\
\hline Bread & 4.456 & 1.673 & Preserved milk & 0.000 & 0.110 & Cabbages & 0.001 & 0.241 \\
\hline Buns, crispbread, biscuits & 0.363 & 0.435 & Yoghurt & 0.443 & 2.121 & Vegetables grown for their fruit & 6.832 & 0.353 \\
\hline Pasta & 0.071 & 0.134 & Cheese & 1.411 & 8.744 & Root crops/bulbs/mushrooms & 0.878 & 1.214 \\
\hline Cakes/puddings & 0.850 & 3.154 & Other milk products & 0.012 & 3.189 & Preserved/processed vegetables & 0.406 & 1.383 \\
\hline Pastry & 0.117 & 1.576 & Eggs & 0.016 & 0.849 & Potatoes & 1.440 & 0.045 \\
\hline Other breads/cereals & 0.019 & 0.977 & Butter & 0.309 & 0.067 & Other tubers & 7.335 & 1.496 \\
\hline Beef & 0.007 & 1.479 & Margarine & 1.415 & 0.598 & Sugar & 0.744 & 0.058 \\
\hline Pork & 6.225 & 1.323 & Peanut butter & 0.230 & 0.027 & Jams, marmalades & 0.214 & 0.039 \\
\hline Lamb & 1.681 & 12.837 & Olive oil & 1.001 & 0.298 & Chocolate & 0.067 & 0.799 \\
\hline Poultry & 0.516 & 10.951 & Edible oils & 0.580 & 0.003 & Confectionery & 1.390 & 0.041 \\
\hline Sausages & 0.181 & 0.582 & Citrus fruits & 2.361 & 0.504 & Edible ices and ice cream & 0.083 & 2.475 \\
\hline Bacon and ham & 1.526 & 4.374 & Bananas & 0.372 & 0.796 & Other sugar products & 0.383 & 0.229 \\
\hline Offal, pâté etc & 0.384 & 0.060 & Apples & 1.744 & 0.124 & Coffee & 0.079 & 4.560 \\
\hline Preserved/processed meat & 7.999 & 0.114 & Pears & 0.307 & 0.422 & Tea & 0.092 & 4.488 \\
\hline Fish & 8.207 & 6.517 & Stone fruits & 5.546 & 0.024 & Mineral or spring waters & 0.009 & 3.076 \\
\hline Seafood & 0.767 & 0.341 & Berries & 4.051 & 0.040 & Soft drinks & 5.403 & 0.548 \\
\hline
\end{tabular}




\begin{tabular}{llllllll} 
Dried/smoked/salted fish and seafood & 1.269 & 0.063 & Other fruits & $\mathbf{1 . 7 9 2}$ & 0.057 & Fruit juices & $\mathbf{2 . 3 9 0}$ \\
Preserved/processed fish & 0.022 & $\mathbf{2 . 4 0 3}$ & Dried fruit and nuts & $\mathbf{3 . 1 7 6}$ & 0.278 & \\
Whole milk & $\mathbf{4 . 0 6 3}$ & $\mathbf{2 . 7 7 5}$ & Preserved fruit & 0.311 & 0.575 & \\
\hline
\end{tabular}

* Bold text indicates above-average contribution to the axis

Table 3 Eigenvalues and percentages of the axes

\begin{tabular}{cccc} 
Axis & Eigenvalue & Percentage & Cumulated Percentage \\
\hline 1 & 0.010 & 49.7 & 49.7 \\
2 & 0.002 & 11.0 & 60.8 \\
3 & 0.002 & 8.5 & 69.3 \\
4 & 0.001 & 6.9 & 76.2 \\
5 & 0.001 & 5.5 & 81.8 \\
6 & 0.001 & 4.9 & 86.6 \\
7 & 0.001 & 4.2 & 90.8 \\
8 & 0.001 & 3.3 & 94.1 \\
9 & 0.000 & 2.4 & 96.6 \\
10 & 0.000 & 2.0 & 98.6 \\
11 & 0.000 & 1.4 & 100.0 \\
\hline
\end{tabular}


Table 4 Relative expenditure on alcoholic drinks at home per annum by class (\%)

\begin{tabular}{|c|c|c|c|c|c|c|c|}
\hline Class fraction & Spirits/ liqueurs & Wine & $\begin{array}{c}\text { Champagne/ } \\
\text { sparkling wines }\end{array}$ & Beer/lager & Other & $\begin{array}{l}\text { Total annual spend } \\
(\mathfrak{E})\end{array}$ & $\mathrm{N}$ (weighted) \\
\hline Business executives & 12.2 & 54.7 & 10.0 & 19.8 & 3.3 & 681 & 1512 \\
\hline Professions & 10.2 & 55.1 & 17.9 & 15.3 & 1.5 & 683 & 704 \\
\hline White collar & 19.9 & 51.3 & 5.7 & 18.1 & 5.0 & 509 & 913 \\
\hline Cultural dominant & 14.5 & 58.1 & 7.1 & 16.1 & 4.2 & 489 & 1635 \\
\hline LMPs & 16.0 & 50.9 & 6.3 & 20.4 & 6.4 & 483 & 929 \\
\hline Administrative & 13.7 & 55.8 & 3.0 & 21.8 & 5.7 & 372 & 792 \\
\hline Technicians & 22.6 & 47.4 & 1.3 & 24.3 & 4.4 & 456 & 1743 \\
\hline Cultural Intermediaries & 12.8 & 57.8 & 3.4 & 22.3 & 3.7 & 452 & 633 \\
\hline Skilled trades & 24.2 & 33.8 & 4.8 & 28.8 & 8.4 & 410 & 1551 \\
\hline Manual labour & 20.0 & 36.3 & 1.0 & 34.7 & 8.0 & 337 & 2636 \\
\hline Sales workers & 26.5 & 39.2 & 3.6 & 25.3 & 5.4 & 314 & 861 \\
\hline Caring services & 18.8 & 36.1 & 4.0 & 33.2 & 7.9 & 357 & 1201 \\
\hline
\end{tabular}


Table 5 Factors mentioned as influences when buying food by class, distance from average proportion (\%)

\begin{tabular}{|c|c|c|c|c|c|c|c|c|c|c|c|c|c|c|}
\hline Class fraction & $\begin{array}{l}\text { Quality/ } \\
\text { freshness }\end{array}$ & Taste & $\begin{array}{l}\text { Healthy } \\
\text { /low fat }\end{array}$ & Presentation & $\begin{array}{l}\text { Vegetarian/ } \\
\text { special diet }\end{array}$ & $\begin{array}{l}\text { Additives/ } \\
\text { E-num }\end{array}$ & $\begin{array}{l}\text { Try new } \\
\text { things }\end{array}$ & Convenience & $\begin{array}{c}\text { Price/value/ } \\
\text { special } \\
\text { offers }\end{array}$ & Organic & $\begin{array}{l}\text { Animal } \\
\text { welfare }\end{array}$ & $\begin{array}{l}\text { Impact/ } \\
\text { fair } \\
\text { trade/local }\end{array}$ & $\begin{array}{l}\text { Impact on } \\
\text { landscape }\end{array}$ & $\begin{array}{c}\text { Packaging } \\
\text { amount/ } \\
\text { type }\end{array}$ \\
\hline Business executives & 3.8 & 10.4 & -1.9 & 2.1 & 2.0 & -1.7 & 1.5 & 14.5 & -6.8 & 3.3 & -0.7 & 10.4 & 1.6 & 0.6 \\
\hline Professions & 4.3 & 15.7 & 16.0 & -2.9 & 5.6 & -0.9 & 6.4 & 14.2 & -11.8 & 5.2 & 12.6 & 9.6 & 0.4 & 8.5 \\
\hline White-collar workers & 3.7 & 14.3 & 8.1 & 0.3 & 3.1 & 4.6 & 4.5 & 3.3 & 1.5 & 7.5 & 5.0 & 8.5 & 3.5 & -3.0 \\
\hline Cultural dominant & 13.9 & 10.7 & 16.1 & 0.3 & 8.5 & 14.0 & -2.6 & -2.3 & -5.0 & 21.3 & 20.7 & 23.0 & 5.0 & 3.5 \\
\hline LMPs & 0.4 & 9.2 & -2.8 & 2.1 & 5.8 & 4.3 & -5.4 & -11.3 & 2.4 & 3.0 & 0.9 & -4.8 & -4.5 & 3.9 \\
\hline Administrative & -0.6 & 3.5 & 0.6 & 0.5 & -1.3 & 2.5 & -0.6 & 7.0 & 2.3 & 1.1 & 2.6 & 1.9 & -0.8 & 0.7 \\
\hline Technicians & 3.9 & 11.5 & 6.9 & 1.7 & -4.2 & 0.2 & -2.4 & 1.3 & -0.3 & -3.2 & 2.8 & 7.9 & -1.5 & -1.6 \\
\hline Cult intermediaries & 2.8 & 8.7 & 1.8 & -0.8 & 6.1 & -0.6 & -3.5 & 9.9 & 3.4 & 0.8 & 9.3 & 3.2 & 3.4 & 2.7 \\
\hline Skilled Trades & -2.4 & -7.0 & -4.6 & -0.3 & -4.6 & -7.6 & 0.4 & -4.0 & -7.3 & -6.4 & -8.6 & -5.0 & 0.7 & 0.8 \\
\hline Manual labour & -6.8 & -8.4 & -9.2 & -1.1 & -2.7 & -4.2 & -1.9 & -3.8 & -0.3 & -6.7 & -11.0 & -11.5 & -1.0 & -5.2 \\
\hline Sales workers & 2.9 & -6.1 & -0.9 & -1.4 & -2.1 & -3.6 & 6.1 & -6.5 & 3.0 & -2.7 & -0.8 & -4.5 & -4.8 & -0.3 \\
\hline Caring services & -1.4 & -9.9 & 5.5 & 1.6 & 1.6 & 3.5 & 1.3 & -3.4 & 10.0 & -1.5 & 5.7 & 1.9 & 0.6 & 6.3 \\
\hline Average & 78.6 & 59.9 & 64.5 & 7.8 & 9.0 & 20.4 & 32.6 & 27.3 & 60.6 & 14.3 & 33.7 & 27.0 & 9.4 & 15.9 \\
\hline
\end{tabular}


Table 6 Favourite type of restaurant by class, distance from average proportion (\%)

\begin{tabular}{|c|c|c|c|c|c|c|c|c|c|c|c|c|}
\hline Class fraction & $\begin{array}{c}\text { Cafe/ } \\
\text { teashop }\end{array}$ & $\begin{array}{l}\text { Pizza } \\
\text { house }\end{array}$ & $\begin{array}{l}\text { Fast } \\
\text { food }\end{array}$ & $\begin{array}{l}\text { Fish and } \\
\text { chips }\end{array}$ & $\begin{array}{c}\text { Pub/ Wine bar/ } \\
\text { Hotel }\end{array}$ & Indian & $\begin{array}{l}\text { Chinese/ } \\
\text { Thai }\end{array}$ & Italian & French & Steakhouse & Vegetarian & None \\
\hline Business execs & -2.9 & -3.0 & -2.7 & -2.3 & -5.0 & 1.4 & -2.5 & 7.8 & 9.3 & -1.2 & 0.0 & 0.9 \\
\hline Professions & -4.3 & -3.0 & -2.7 & -2.3 & -11.0 & -3.5 & 1.7 & 12.4 & 19.4 & -2.1 & -2.7 & -1.8 \\
\hline White collar & -1.8 & -1.7 & -1.4 & -1.0 & -10.3 & -3.5 & -0.1 & 18.4 & 6.7 & -3.0 & -0.2 & -1.8 \\
\hline Cultural dominant & -2.6 & -0.4 & -1.8 & -1.4 & -6.3 & 2.5 & 4.6 & 1.6 & 6.8 & -6.3 & 3.4 & -0.1 \\
\hline LMPs & 2.3 & -3.0 & -2.7 & 4.3 & -4.8 & -2.5 & 2.4 & 2.3 & 6.0 & -3.1 & -1.1 & -0.2 \\
\hline Administrative & -1.4 & -1.6 & 0.7 & -0.9 & 7.0 & -0.3 & 0.3 & 0.8 & 0.6 & -2.2 & -1.7 & -1.3 \\
\hline Technicians & -4.3 & 2.9 & -2.7 & -0.3 & -7.1 & 3.4 & 4.6 & 1.6 & 2.7 & -0.2 & -0.7 & 0.2 \\
\hline Cultural intermediaries & -0.2 & -1.6 & 0.0 & -2.3 & 0.5 & 0.0 & -6.6 & 10.6 & 1.1 & 0.2 & 0.0 & -1.8 \\
\hline Skilled trades & -0.1 & 0.6 & 2.1 & -0.5 & 5.9 & -0.3 & -0.9 & -8.1 & -4.7 & 8.8 & -2.1 & -0.6 \\
\hline Manual labour & 2.3 & 0.6 & 1.2 & 2.4 & 0.9 & 0.4 & -2.1 & -4.5 & -5.2 & 0.3 & 1.7 & 2.1 \\
\hline Sales workers & 1.9 & 3.9 & -2.0 & -0.2 & -0.7 & 2.9 & 0.4 & -5.1 & -3.0 & 3.7 & -1.3 & -0.4 \\
\hline Caring services & 0.3 & 0.9 & 1.9 & -1.0 & 1.5 & -3.1 & 3.5 & -0.3 & -1.8 & -2.1 & 0.6 & -0.5 \\
\hline Average & 4.3 & 3.0 & 2.7 & 2.3 & 22.8 & 12.3 & 18.9 & 14.1 & 7.1 & 8.0 & 2.7 & 1.8 \\
\hline
\end{tabular}

